\title{
Structure and Properties of Functionalized Porous Silica Hybrid Materials
}

\author{
Elena V. Todorova, Georgi E. Chernev, Stoqn P. Djambazov \\ Department "Silicate technology", University of Chemical Technology and Metallurgy, Sofia, Bulgaria \\ Email: elena.todorova.uctm@gmail.com
}

Received 20 May 2014; revised 19 June 2014; accepted 17 July 2014

Copyright (C) 2014 by authors and Scientific Research Publishing Inc.

This work is licensed under the Creative Commons Attribution International License (CC BY). http://creativecommons.org/licenses/by/4.0/

c) (i) Open Access

\begin{abstract}
Functionalized silica hybrid materials are extensively studied and applied materials in the field of science and technology. Functionalization is an approach, which allows for the application of organic components in the improvement of the design, properties and potential application of silicate materials. Silica hybrid materials, functionalized via incorporation of organic components (chitosan and methacrylic acid) were synthesized by the sol-gel method. The base silica structure of the hybrids was obtained via hydrolysis and condensation of the silicate precursor, tetraethyl orthosilicate. The investigations of synthesized hybrids are focused on the influence of the nature and quantity of functional organic components on their final structures and properties. The structural characteristics of obtained hybrid materials were investigated using XRD, FTIR, SEM and DTA/TG analysis. The obtained results presented the formation of amorphous porous structure and the organic components are evenly distributed into the silica network. The functional radicals of chitosan and methacrylic acid (amine, hydroxyl groups) exist in the hybrid structure as free reactive centers, as their quantity increases with increasing the organic amount. The swelling behavior in acidic and neutral solutions of the synthesized materials is investigated and the results presented, that the silicate materials exhibit hydrophilic character.
\end{abstract}

\section{Keywords}

Sol-Gel, Silica Hybrids, Functionalization, Porosity, Biomaterials

\section{Introduction}

Science and technology leads to the improvement of materials, which are able to cater for present and pressing needs. Hybrid materials play an important role for this purpose due to the possibility of combining suitable properties in one structure. These materials should cover the application requirements, as well as be accessible, reusable and cost-effective [1] [2]. 
Synthesis of hybrid materials with diverse properties can be achieved via a modification of inorganic structure with organic components. The proposed system can combine inorganic stability and durability with plasticity and specific properties normally associated with organic materials. Functionalization of the inorganic structure is an approach, which allows for obtaining hybrid materials with improved behavior and application [3] [4]. Functional hybrids can successfully be applied in any field, which requires contact interactions on the surface (environmental remediation, immobilization of biomolecules, etc.) [5]-[7].

Important determinants in the development of functional hybrids are the preparation technique(s) and precursor material behavior. Requirements such as low-cost, easy preparation and accessible equipment also reduce the variety of synthesis routes. One route, which covers all of the above requirements, is that of sol-gel synthesis. This technique allows preparation of different compositions, independently of the state (amorphous, crystal), which is required, as well as controlling each step of the process [8]. Most of the materials, whose structures can easily be modified with different functional radical, and prepared via sol-gel synthesis, are silicates [9] [10].

The silicates are inorganic components, which can easily be transformed from precursor into monolith, porous, thin film or coating material. Silica materials possess high thermal resilience and can withstand high pressures and external aggressive materials and media [11] [12]. Regardless of the silica stability their application is limited, due to reduce pollutant reactivity and degradability. Therefore, a combination with suitable organic components serves as a great opportunity to improve the plasticity and stability of the silica structure, and to improve contact behavior with external moieties [13].

Acrylates are synthetic organic components known as good film formers, with high mechanical stability [14] [15]. In polymerized form, acrylates have been proven to be excellent protective materials, but limitations such as poor water and temperature resistance reduces their potential applications. Combinations of acrylate with silica components allow for the formation of hybrids with improved long-term stability and durability [16]. The application of these hybrid materials is connected to the free reactive groups of the acrylate. Acrylates with long chain structures or further polymerization have fewer free reactive centers and a consequently reduced potential application. Furthermore, the hydrophilicity also decreases when the acrylate chain is longer and this causes an unfavorable effect on possible interactions with external molecules [17]. Methacrylic acid is a suitable acrylate which in combination with silica material will lead to the realization of a hybrid with improved stability, resistance and available functional groups. The structure of this organic material contains carboxylic group, which can be dissociated into $\mathrm{C}_{3} \mathrm{H}_{5} \mathrm{COO}^{-}$anion and $\mathrm{H}^{+}$cation. In addition the carboxyl groups can easily interact with amine functionalized biomolecules for immobilization purposes or cationic pollutants (heavy metals). Addition of MA into silica network leads to the formation of a hybrid with improved functionality and hydrophilicity [18] [19]. Nevertheless the variety of high functionalized centers is limited due to the dissociation possibility of carboxylic groups in different media, as well as contact only with cationic molecules [20] [21]. Preparation of silica hybrid material with improved functionalized surface and the ability to interact with different types of external molecules can be obtained with a combination of another organic component [22].

Natural organic components are suitable materials, due to their biocompatibility, degradability, non-toxicity and abundance. The investigations focused on preparation of functional materials for environmental or immobilization purposes established that the existence of free amine groups play an important role in interactions with external moieties like waste water pollutants or biomolecules. One of the most abundant natural organic materials is chitosan, whose structure contains free amine and hydroxyl groups, which act as reactive centers [23]. In acidic solutions, the attraction process with pollutants is increased from protonation of amine groups [24].

The preparation of a silica network matrix into which the organic components (chitosan and methacrylic acid) are evenly distributed as separate units can lead to the formation of an innovative hybrid material with improved functionality. The use of the full qualities of the organic components allows for the formation of a material suitable for different pollutants/biomolecules.

Silica hybrid materials, modified by addition of chitosan and methacrylic acid organic components were synthesized via the sol-gel method. Characterization of the structure by XRD, FTIR, SEM and DTA/TG analysis was conducted to determine the structural nature of the hybrid material, as well as the influence of the used components.

\section{Materials and Methods}

\subsection{Materials}

Tetraethyl orthosilicate (TEOS, 98\%, Sigma Aldrich), chitosan (CS, degree of deacetylation 75\% - 85\%, Fluka), 
methacrylic acid (MA, Fluka), $\mathrm{dH}_{2} \mathrm{O}, \mathrm{HCl}$ (37\%, Merck) and acetic acid (99\%, Sigma Aldrich) were the initial components for preparation of the innovative silica hybrid materials.

\subsection{Synthesis Procedure}

Functionalized hybrid materials based on silicates with participation of organic components (CS and MA) was synthesized via the sol-gel method. The first step of the preparation process is the hydrolysis of the silica source (TEOS) using $\mathrm{d}_{2} \mathrm{O}$, and $\mathrm{HCl}$ as a catalyst. After mixing the components and stirring with a magnetic stirrer for $1 \mathrm{~h}$, a silica sol is obtained. For better distribution and compatibility of CS in the hybrid structure this polysaccharide was dissolved in 1\% acetic acid. After complete dissolution (30 min via vigorous stirring), a calculated amount of CS solution was added to the silica sol. Immediately after the addition of CS, an equal amount of MA was added and the solution was stirred for another $30 \mathrm{~min}$. The obtained homogeneous sols were poured onto Petri dishes, where the hybrid material transformed into gels. The realized gels were then dried at room temperature. To establish the compatibility of the used components, and the influence of organic components on hybrid structures, five samples with different organic quantities were synthesized: TEOS/CS/MA = 1:0.1:0.1 (SiCSMA1); $\mathrm{TEOS} / \mathrm{CS} / \mathrm{MA}=1: 0.2: 0.2$ (SiCSMA2); $\mathrm{TEOS} / \mathrm{CS} / \mathrm{MA}=1: 0.3: 0.3$ (SiCSMA3); $\mathrm{TEOS} / \mathrm{CS} / \mathrm{MA}=$ 1:0.4:0.4 (SiCSMA4); TEOS/CS/MA = 1:0.5:0.5 (SiCSMA5).

\subsection{Structural Characterization}

The structural characteristics of the synthesized hybrid materials are crucial in determining their suitability for their intended application. XRD (Brucker D8 Advance; $\mathrm{Cu}-\mathrm{K} \alpha$ radiation with scan rate of $0.02^{0} \cdot \mathrm{min}^{-1}$ in $2 \theta$ range between $10^{\circ}$ and $80^{\circ}$.) was used to determine the state of the obtained hybrid materials. The specific groups of used components and chemical bonds formed via sol-gel synthesis were observed via FTIR analysis (MATTSON 7000, BRUKER TENSOR 27 Spectrometer, $4000-400 \mathrm{~cm}^{-1}$ ). SEM (Hitachi SU-70) analysis was used for observation of prepared silica hybrid structures. For understanding the thermal stability of obtained hybrids DTA/TG (Setaram Labsys ${ }^{\mathrm{Tm}} \mathrm{TG}-\mathrm{DSC} 16$, temperature diapason $0^{\circ} \mathrm{C}-1000^{\circ} \mathrm{C}$, heating rate $10^{\circ} \mathrm{C} / \mathrm{min}$ ) analysis was used.

\subsection{Swelling Measurement}

To establish the influence of the CS and MA organic components on the properties of the synthesized silica hybrid materials their swelling behavior in different media (acidic $(1 \mathrm{M} \mathrm{HCl}, \mathrm{pH}=3)$ and distilled water $(\mathrm{pH}=7)$ solutions) was analyzed. Obtained silica hybrid materials with known weight $\left(\mathrm{M}_{1}\right)$ were immersed in the solutions $(10 \mathrm{ml})$ at an ambient temperature for $24 \mathrm{~h}$. Afterwards, the samples were removed, dried and measured again $\left(\mathrm{M}_{2}\right)$. The weight change percentage $(\mathrm{W}, \%)$ was calculated according to the Equation (1) :

$$
\mathrm{W}=\frac{\mathrm{M}_{2}-\mathrm{M}_{1}}{\mathrm{M}_{1}} \times 100
$$

\section{Results and Discussion}

The state of the synthesized hybrid materials was evaluated via XRD analysis. The results (Figure 1) showed presence of wide range peak around $232 \theta$ and low intensive peak $\sim 122 \theta$. Preparation of hybrid materials based on TEOS and using sol-gel synthesis at room temperature lead to the formation of a silica network in an amorphous state. XRD patterns proved the formation of amorphous silica structure with presence of wide range peak around $232 \theta$. The organic component chitosan can exist in three different forms-noncrystalline (11.7 2 $\theta$ ),

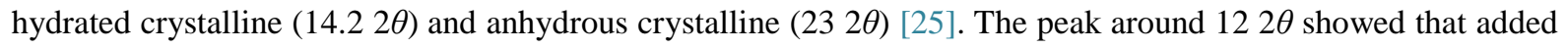
CS is in amorphous form.

The establishment of the structural groups in the obtained hybrid materials via FTIR analysis gives information about the influence of the used preparation technique and component behaviour (Figure 2(a)). Intensive peaks at 450 and 550, as well as $1090 \mathrm{~cm}^{-1}$ are associated with silica symmetric and asymmetric stretching vibrations, respectively. Presence of characteristic Si-O-Si bonds showed the successful formation of a hybrid material on the silica based of network. Existence of free Si-OH groups associated with the peak at $950 \mathrm{~cm}^{-1}$ are due to incomplete condensation reaction of available silanol units [26]. Free hydroxyl groups play favourable 


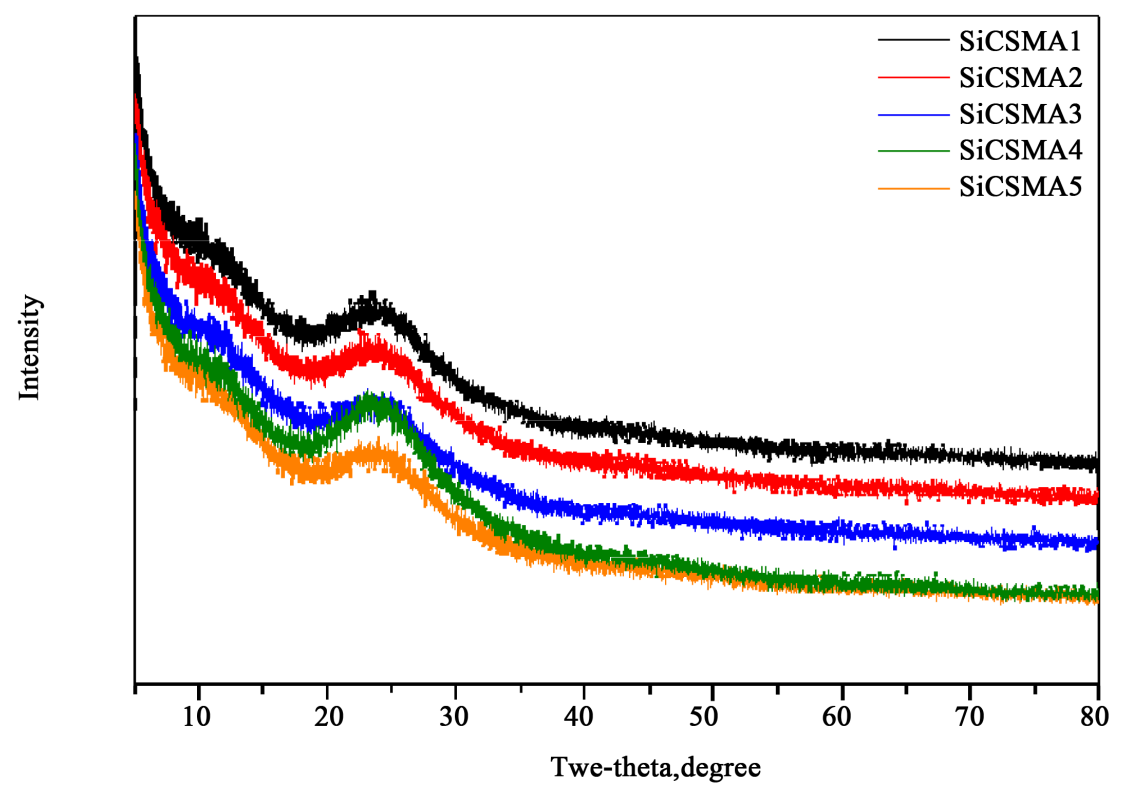

Figure 1. XRD patterns of obtained silica hybrid materials.

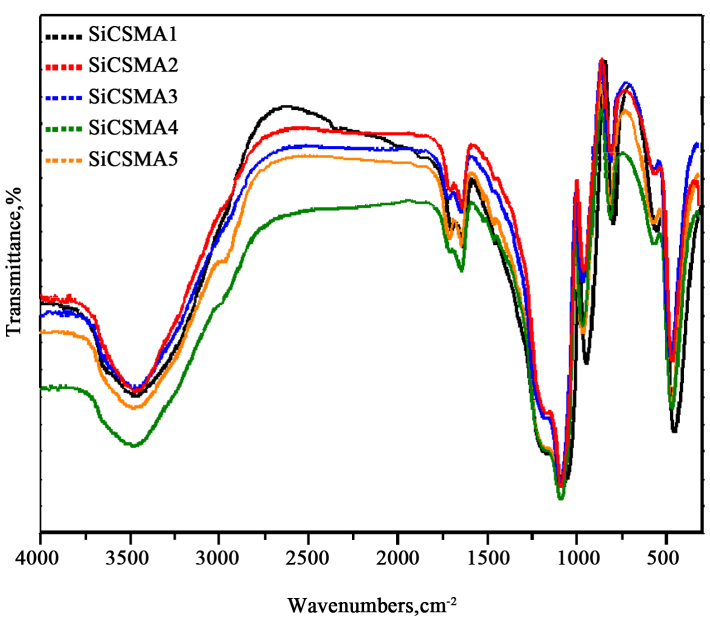

(a)

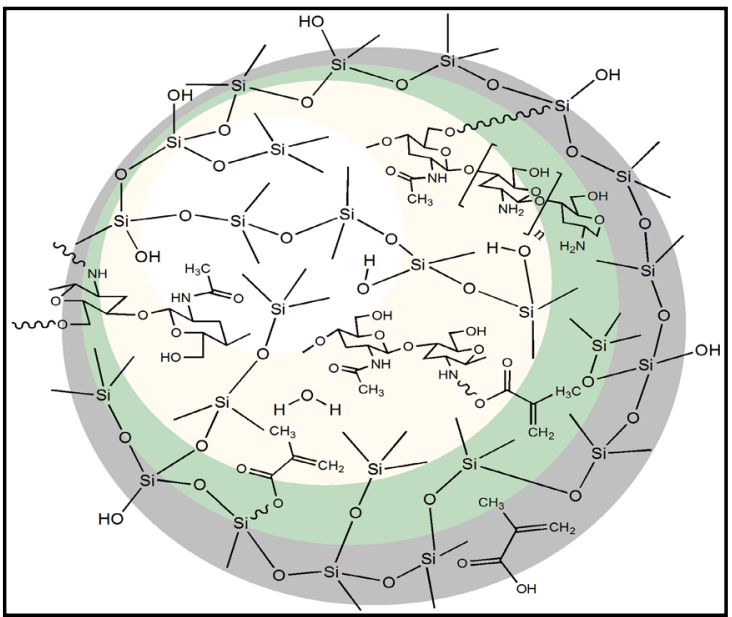

(b)

Figure 2. FTIR spectra (a) and model structure (b) of synthesized silica hybrid materials.

affect on the functionality of prepared silica hybrid materials. Another characteristic peaks for sol-gel synthesis at room temperature are of water molecules and on the FTIR spectra corresponding to the peaks at 1640 and the wide range peak at $3400 \mathrm{~cm}^{-1}$. Characteristic peaks of used organic components are also observed on FTIR spectra of synthesized hybrids. The peak around $1200 \mathrm{~cm}^{-1}$ is assigned to the asymmetric stretching of C-O-C bridge chain of chitosan [27]. Symmetric deformations of $-\mathrm{CH}_{3}$ and $-\mathrm{CH}_{2}$ groups of $\mathrm{CS}$ and MA are assigned with the peaks at 1460 and $2980 \mathrm{~cm}^{-1}$ [28]. Existences of characteristic free reactive groups of CS (N-H and $-\mathrm{OH}$ ) are associated with peaks at 1520 and in the range $3400 \mathrm{~cm}^{-1}$ [29]. Specific $\mathrm{C}=\mathrm{C}$ group of MA structure is associated with peak at $1640 \mathrm{~cm}^{-1}$. Functional carboxylic group of synthetic organic component is associated with the peak at $1710 \mathrm{~cm}^{-1}$ [30].

FTIR spectra showed that the synthesized hybrid materials are based on silica network into which the organic components are successfully incorporated. Hydroxyl, carboxyl and amine groups, which were found to be existent in the hybrid structures proved, that the synthesized innovative hybrids can be applied for immobilization purposes or used as protective materials. The free reactive centres allows for interactions with cationic and anionic external moieties. Model structure and possible interactions between the used components of obtained silica 
hybrid materials is shown on Figure 2(b).

The structure of the obtained silica hybrid materials was observed via SEM analysis (Figure 3). Different structures with varying porosities were obtained as a result of the variation of the compositions of the organic components. The obtained micrographs presented formation of homogeneous materials due to preparation of silica network with pores all over the entire structure as a result of used MA component [31]. The pore size of SiCSMA1 samplel varied between 4 and $10 \mu \mathrm{m}$. With an increasing of the amount of organic component, the pore size increased up to $50 \mu \mathrm{m}$ (SiCSMA5), and their quantity decreased.

The obtained results from SEM analysis posses influence of organic nature on the final structures. The organic components added into the hybrid materials lead to the formation of porous structures with improve functional contact surface area. For preparation of high reactive materials, which can easily attract and interact with external molecules, MA and CS are suitable candidates for that purpose.

The behavior of the obtained hybrid materials during thermal treatment was determined using DTA analysis. TG analysis showed weight loss of the hybrids through the temperature diapason $0^{\circ} \mathrm{C}-1000^{\circ} \mathrm{C}$. For a better un-
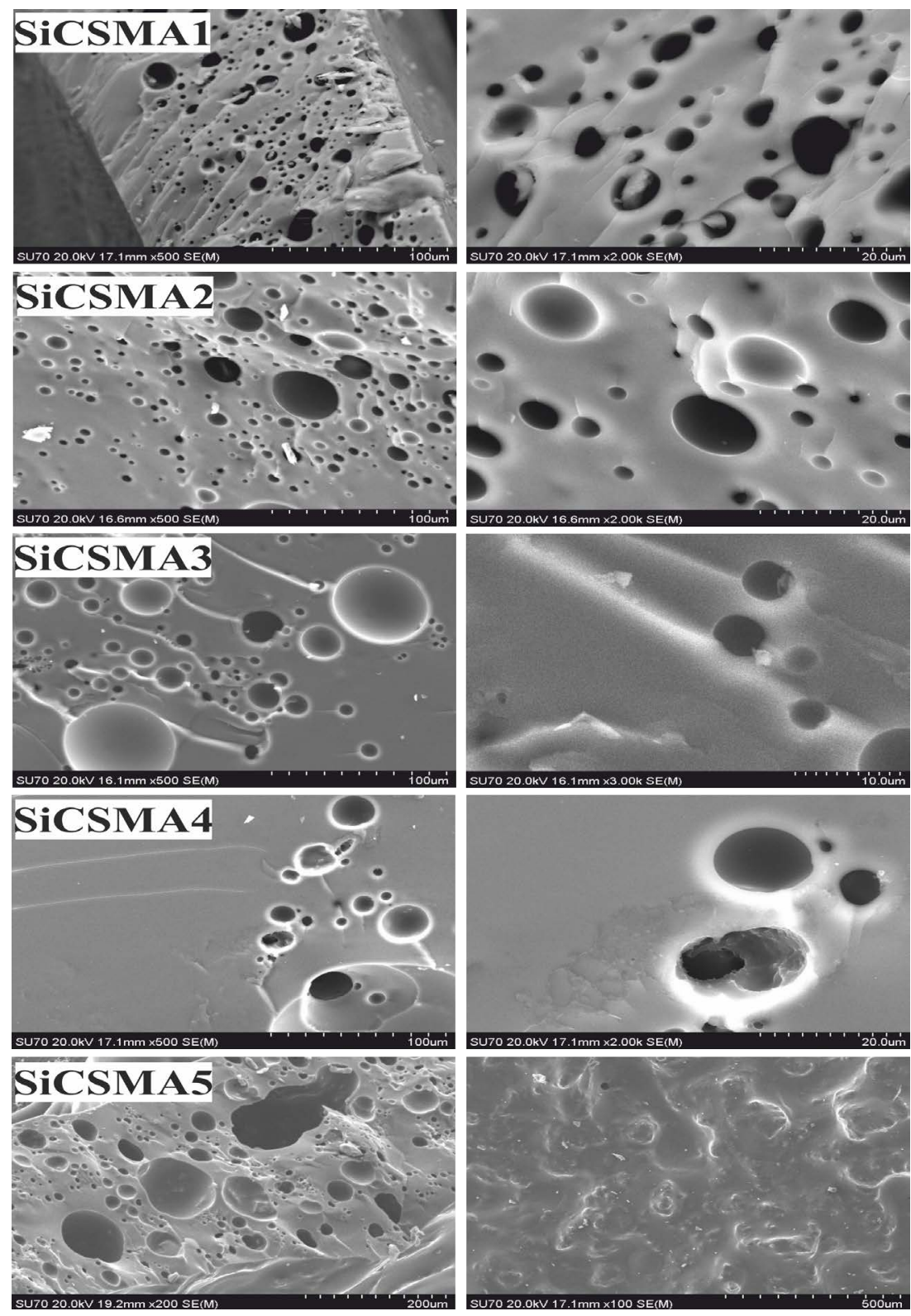

Figure 3. SEM micrographs of obtained silica hybrid surfaces. 
derstanding of the influence of CS and MA on the structure and properties of hybrid materials, sample SiCSMA5 and pure silica were tested (Figure 4).

DTA thermograph of pure silica sample showed intensive endothermic reaction around $130^{\circ} \mathrm{C}$. The endothermic reaction is correlated to the evaporation of adsorbed and chemically bonded water molecules. This can be proved with drastically weight loss in the temperature diapason $50^{\circ} \mathrm{C}-200^{\circ} \mathrm{C}$. After $130^{\circ} \mathrm{C}$ condensation of silanol units and self-compacting of the hybrid material is observed. Maximum weight loss of pure silica material established from TG analysis is $22 \%$. The obtained weight loss results clearly demonstrated the effect of the preparation technique-sol-gel synthesis at room temperature (Figure 4(a)).

The DTA/TG curves for sample SiCSMA5 presented intensive endothermic reaction around $105^{\circ} \mathrm{C}$ and weight loss 30\% (Figure 4(b)). The reduce temperature of the reaction is associated with addition of organic components in the silica material, which leads to decreasing of the thermal stability. The reaction occurred with lower thermal energy due to the big quantity of organic components. Furthermore, the results presented, that the CS and MA units are located on the hybrid surface and their degradation is favored. Maximum weight loss (30\%) is associated with evaporation of adsorbed water molecules and degradation of organic components.

The swelling behavior of the synthesized porous hybrids was tested via weight change percentage (W, \%) by immersion in acidic and neutral solutions and the obtained results are presented on Figure 5. The results of swelling test showed the different behavior of the synthesized hybrid structures by variation of $\mathrm{pH}$.

In acidic and neutral solutions the weight change percent of pure silica is $2.96 \%$ and $2.03 \%$, respectively. The weight change of the pure silica presented the low hydrophilicity of the silica network. The attraction of the water molecules activated by silanol groups ( $\mathrm{Si}-\mathrm{OH})$ kept due to the sol-gel synthesis at room temperature [32]. The addition of organic components led to improving the swelling behavior due to formation of porous materials with improves contact surface area (established via SEM micrographs). Furthermore, the hydrophilic character of the used organic components, as well as functional reactive centers (established via FTIR spectra) improve the contact with the water molecules [33]. Functional carboxylic groups of MA dissociated into COO-anion and $\mathrm{H}+$ cation [34]. Hydroxyl and amine groups of CS, as well as-OH groups bonded with $\mathrm{Si}$ atoms also attract the water molecules, as a result of which the weight increase. In acidic media the $\mathrm{W}$ values are higher, than these of hybrid weight in neutral solution and can be associated with swelling behavior of CS units into solutions with different $\mathrm{pH}$ [35]. In acidic conditions the CS units expanded, as a result of which penetration of water molecules is, favor [36]. In both media the swelling tests presented that with increasing of the organic amount the weight of the hybrid materials also increase. The results showed that the functionalization of silica network (known as hydrophobic material) play important role for further application of the synthesized hybrids [37]. The organic components, which are proven as hydrophilic materials improve the hydrophilicity of the hybrid structures, which plays favorable effect on the interactions with external molecules [38]-[40].

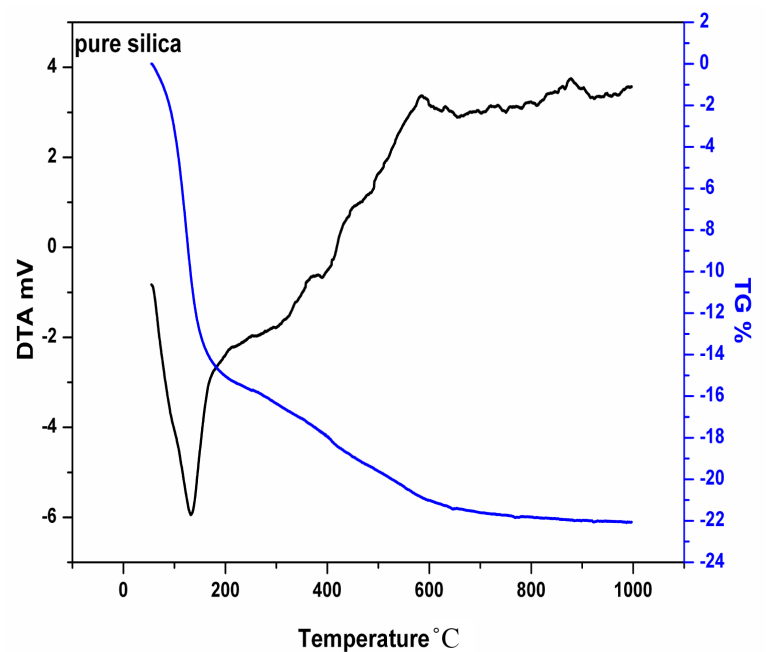

(a)

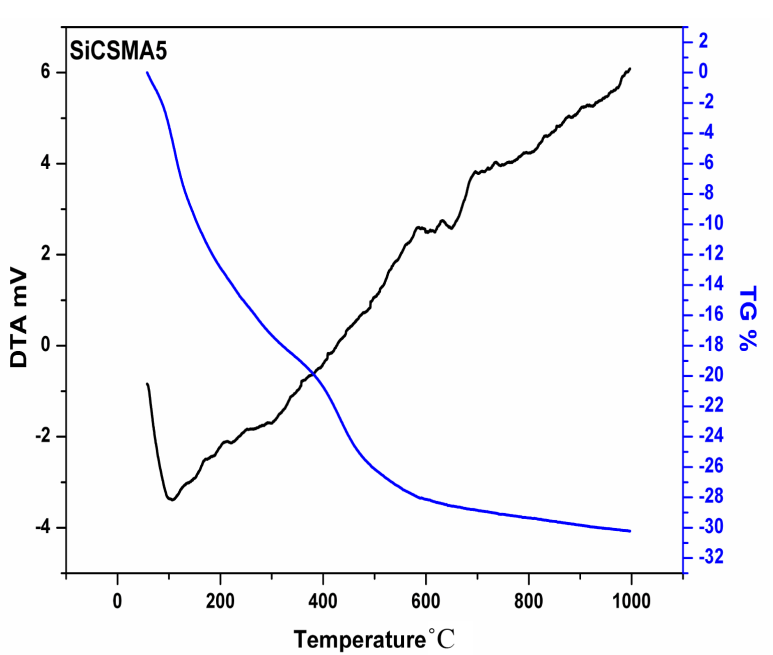

(b)

Figure 4. DTA/TG curves of pure silica (a) and SiCSMA5 hybrid material (b). 


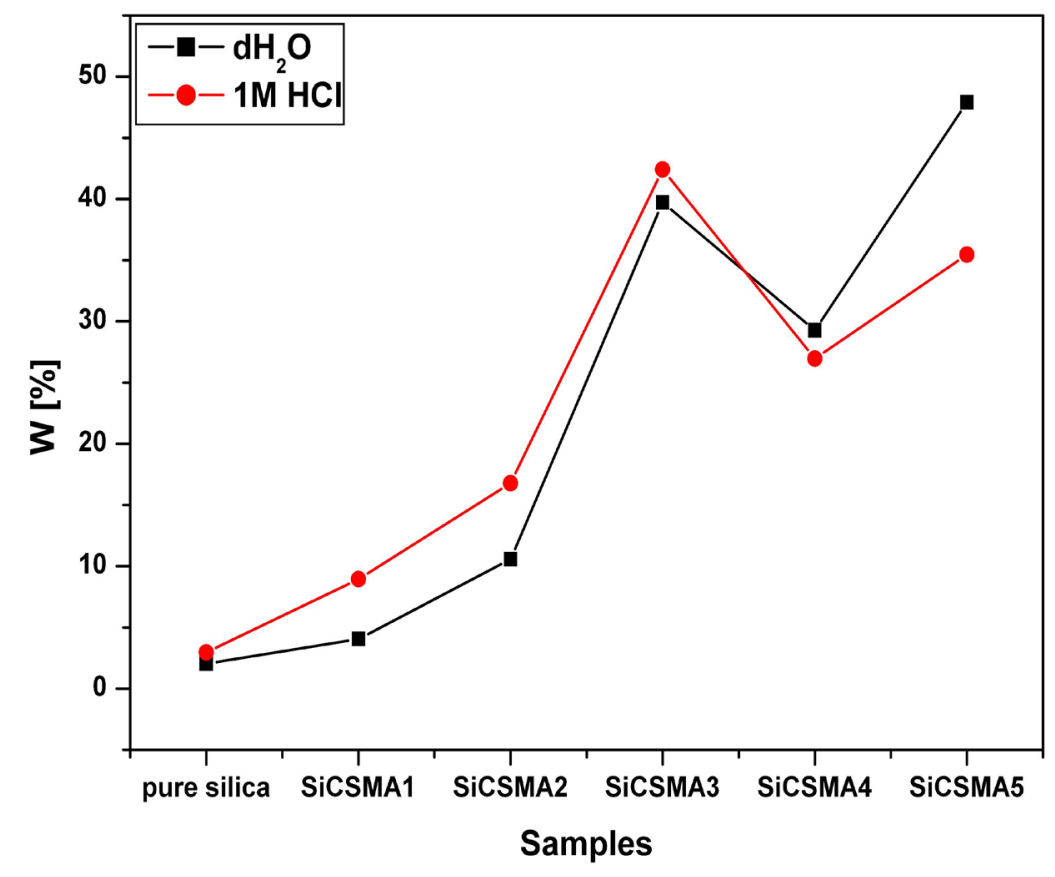

Figure 5. Results of swelling test of the synthesized silica hybrid materials.

\section{Conclusion}

Porous hybrid materials with functional surfaces were obtained via incorporation of CS and MA in a silica network. Functionalized silica materials synthesized by the sol-gel technique are amorphous with large surface contact area and exhibit hydrophilicity and thermal stability. The obtained hybrid materials showed good stability in acidic and neutral solutions, where the functional units as free reactive centers can interact with external moieties. The investigations of the structure and properties of synthesized silica/CS/MA materials showed, that these functionalized hybrids can be successfully applied for the immobilization of different biomolecules or as adsorbents of pollutants.

\section{Acknowledgements}

This material has been published with the support of a project BG051P0001/3.3-05-001 "Science and business”, financed by Operational programme "Human Resources Development” to European Social Fund.

\section{References}

[1] Lee, K., Morad, N., Teng, T. and Poh, B. (2012) Development, Characterization and the Application of Hybrid Materials in Coagulation/Flocculation of Wastewater: A Review. Chemical Engineering Journal, 203, 370-386. http://dx.doi.org/10.1016/j.cej.2012.06.109

[2] Xia, K., Ferguson, R., Losier, M., Tchoukanova, N., Brüning, R. and Djaoueda, R. (2010) Synthesis of Hybrid Silica materials with Tunable Pore Structures and Morphology and Their Application for Heavy Metal Removal from Drinking Water. Journal of Hazardous Materials, 183, 554-564. http://dx.doi.org/10.1016/j.jhazmat.2010.07.060

[3] Wang, T., Chen, Y., Ma, Y., Chen, M., Nie, C., Hu, M., Li, Y., Jia, Z., Fang, J. and Gao, H. (2013) Ampholine-Functionalized Hybrid Organic-Inorganic Silica Material as Sorbent for Solid-Phase Extraction of Acidic and Basic Compounds. Journal of Chromatography A, 1308, 63-72. http://dx.doi.org/10.1016/j.chroma.2013.08.025

[4] Miao, T. and Wang, L. (2007) Immobilization of Copper in Organic-Inorganic Hybrid Materials: A Highly Efficient and Reusable Catalyst for the Ullmann Diaryl Etherification. Tetrahedron Letters, 48, 95-99. http://dx.doi.org/10.1016/j.tetlet.2006.11.001

[5] Hu, Y., Tang, S., Jiang L., Zou, B., Yang, J. and Huang, H. (2012) Immobilization of Burkholderia Cepacia Lipase on Functionalized Ionic Liquids Modified Mesoporous Silica SBA-15. Process Biochemistry, 47, 2291-2299. http://dx.doi.org/10.1016/j.procbio.2012.09.007 
[6] Crippa, M., Callone, E., D’Arienzo, M., Müller, K., Polizzi, S., Wahba, L., Morazzoni, F. and Scotti, R. (2011) TiO2 Nanocrystals Grafted on Macroporous Silica: A Novel Hybrid Organic-Inorganic Sol-Gel Approach for the Synthesis of Highly Photoactive Composite Material. Applied Catalysis B: Environmental, 104, 282-290. http://dx.doi.org/10.1016/j.apcatb.2011.03.018

[7] Tang, H., Guo, J., Sun, Y., Chang, B., Ren, Q. and Yang, W. (2011) Facile Synthesis of pH Sensitive Polymer-Coated Mesoporous Silica Nanoparticles and Their Application in Drug Delivery. International Journal of Pharmaceutics, 421, 388-396. http://dx.doi.org/10.1016/j.ijpharm.2011.10.013

[8] O’Brien, S., Copuroglu, M. and Crean, G.M. (2007) Effects of Refractive Index Modifiers and UV Light on an Epoxyfunctional Inorganic-Organic Hybrid Sol-Gel Derived Thin Film System. Applied Surface Science, 253, 7969-7972. http://dx.doi.org/10.1016/j.apsusc.2007.02.202

[9] Liu, J., Xu, S. and Yan, B. (2011) Photoactive Hybrids with the Functionalized Schiff-Base Derivatives Covalently Bonded Inorganic Silica Network: Sol-Gel Synthesis, Characterization and Photoluminescence. Colloids and Surfaces A: Physicochemical Enineering Aspects, 373, 116-123. http://dx.doi.org/10.1016/j.colsurfa.2010.10.036

[10] Yen, M. and Kuo, M. (2012) Sol-Gel Synthesis of Organiceinorganic Hybrid Materials Comprising Boehmite, Silica, and Thiazole Dye. Dyes and Pigments, 94, 349-354.

[11] Hasanzadeh, M., Shadjou, N., Eskandani, M. and Guardia, M. (2012) Mesoporous Silica-Based Materials for Use in Electrochemical Enzyme Nanobiosensors. Trends in Analytical Chemistry, 40, 106-118. http://dx.doi.org/10.1016/j.trac.2012.06.007

[12] Hao, J., Han, M., Wang, C. and Meng, X., Enhanced Removal of Arsenite from Water by a Mesoporous Hybrid Material-Thiol-Functionalized Silica Coated Activated Alumina. Microporous and Mesoporous Materials, 124, 1-7.

[13] Wang, D., Zhang, J., Tian, X., Liu, D. and Sumathy, K. (2014) Progress in Silica Gel-Water Adsorption Refrigeration Technology. Renewable and Sustainable Energy Reviews, 30, 85-104. http://dx.doi.org/10.1016/j.rser.2013.09.023

[14] Yuan, Y., Liu, R., Wang, C., Luo, J. and Liu, X. (2014) Synthesis of UV-Curable Acrylate Polymer Containing Sulfonic Groups for Anti-Fog Coatings. Progress in Organic Coatings, in press. http://dx.doi.org/10.1016/j.porgcoat.2014.01.001

[15] Nollenberger, K. and Albers, J. (2013) Poly(meth)acrylate-Based Coatings. International Journal of Pharmaceutics, 457, 461-469. http://dx.doi.org/10.1016/j.ijpharm.2013.09.029

[16] Liao, W., Qu, J., Li, Z. and Chen H. (2010) Preparation of Organic/Inorganic Hybrid Polymer Emulsions with High Silicon Content and Sol-Gel-Derived Thin Films. Chinese Journal of Chemical Engineering, 18, 156-163. http://dx.doi.org/10.1016/S1004-9541(08)60337-7

[17] Liu, J., Ma, J., Bao, Y., Zhu, Z., Zhang, J. and Ma, J. (2011) Effect of Long-Chain Acrylate on the Properties of Polyacrylate/Nano-SiO ${ }_{2}$ Composite Leather Finishing Agent. Polymer-Plastics Technology and Engineering, 50, $1546-1551$. http://dx.doi.org/10.1080/03602559.2011.603782

[18] Mitchell, J.S. (2011) Spin-Coated Methacrylic Acid Copolymer Thin Films for Covalent Immobilization of Small Molecules on Surface Plasmon Resonance Substrates. European Polymer Journal, 47, 16-23. http://dx.doi.org/10.1016/j.eurpolymj.2010.10.028

[19] Sevšek, U. and Krajnc, P. (2012) Methacrylic Acid Microcellular Highly Porous Monoliths: Preparation and Functionalisation. Reactive \& Functional Polymers, 72, 221-226. http://dx.doi.org/10.1016/j.reactfunctpolym.2012.02.007

[20] An, F., Feng, X. and Gao, B. (2010) Adsorption Property and Mechanism of Composite Adsorbent $\mathrm{PMAA}_{\mathrm{S}} \mathrm{SiO}_{2}$ for Aniline. Journal of Hazardous Materials, 178, 499-504. http://dx.doi.org/10.1016/j.jhazmat.2010.01.109

[21] Panic, V.V., Madzarevic, Z.P., Volkov-Husovic, T. and Velickovic, S.J. (2013) Poly(Methacrylic Acid) Based Hydrogels as Sorbents for Removal of Cationic Dye Basic Yellow 28: Kinetics, Equilibrium Study and Image Analysis. Chemical Engineering Journal, 217, 192-204. http://dx.doi.org/10.1016/j.cej.2012.11.081

[22] Anirudhan, T.S. and Rijith, S. (2012) Synthesis and Characterization of Carboxyl Terminated Poly(Methacrylic Acid) Grafted Chitosan/Bentonite Composite and Its Application for the Recovery of Uranium(VI) from Aqueous Media. Journal of Environmental Radioactivity, 106, 8-19. http://dx.doi.org/10.1016/j.jenvrad.2011.10.013

[23] Kwok, K.S., Koong, L.F., Chen, G. and McKay, G. (2014) Mechanism of Arsenic Removal Using Chitosan and Nanochitosan. Journal of Colloid and Interface Science, 416, 1-10. http://dx.doi.org/10.1016/j.jcis.2013.10.031

[24] Khalek, M.D., Mahmoud, G.A. and El-Kelesh, N.A. (2012) Synthesis and Characterization of Poly-Methacrylic Acid Grafted Chitosan-Bentonite Composite and Its Application for Heavy Metals Recovery. Chemistry and Materials Research, 2, 1-12.

[25] Song, R., Xue, R., He, L., Liu, Y. and Xiao, Q. (2008) The Structure and Properties of Chitosan/Polyethyleneglycol/Silica Ternary Hybrid Organic-Inorganic Films. Chinese Journal of Polymer Science, 26, 621-630. http://dx.doi.org/10.1142/S0256767908003357 
[26] Lee, E., Jun, S., Kim, H., Kim, H., Koh, Y. and Jang, J. (2010) Silica Xerogel-Chitosan Nano-Hybrids for Use as Drug Eluting Bone Replacement. Journal of Material Science: Material Medicine, 21, 207-214. http://dx.doi.org/10.1007/s10856-009-3835-9

[27] Sivakami, M.S., Gomathi, T., Venkatesan, J., Jeong, H., Kim, S. and Sudha, P.N. (2013) Preparation and Characterization of Nano Chitosan for Treatment Wastewaters. International Journal of Biological Macromolecules, 57, $204-212$. http://dx.doi.org/10.1016/j.ijbiomac.2013.03.005

[28] Abdel-Raouf, M.E., Abdul-Raheim, A.M., El-Kafrawy, A.F., Maysour, N.E., Ibraheim, A.K. and Abdel-Azim, A.A. (2013) PHEMA Magnetic Nanogels for Removal of Cu(II) Ions from Aqueous Solution. International Journal of Chemistry and Material Science, 1, 36-44.

[29] Kyzas, G.Z. and Lazaridis, N.K. (2009) Reactive and Basic Dyes Removal by Sorption onto Chitosan Derivatives. Journal of Colloid and Interface Science, 331, 32-39. http://dx.doi.org/10.1016/j.jcis.2008.11.003

[30] Mahmoodian, H., Moradi, O. and Shariatzadeh, B. (2014) Grafting Chitosan and PolyHEMA on Carbon Nanotubes Surfaces: “Grafting to” and “Grafting from” Methods. International Journal of Biological Macromolecules, 63, 92-97. http://dx.doi.org/10.1016/j.ijbiomac.2013.10.030

[31] Deng, W., Li, R., Zhang, M., Gong, L. and Kan, C. (2010) Influences of MAA on the Porous Morphology of P(StMAA) Latex Particles Produced by Batch Soap-Free Emulsion Polymerization Followed by Stepwise Alkali/Acid Post-Treatment. Journal of Colloid and Interface Science, 349, 122-126. http://dx.doi.org/10.1016/j.jcis.2010.05.033

[32] Purcar, V., Stamatin, I., Cinteza, O., Petcu, C., Raditoiu, V., Ghiurea, M., Miclaus, T. and Andronie, A. (2012) Fabrication of Hydrophobic and Antireflective Coatings Based on Hybrid Silica Films by Sol-Gel Process. Surface and Coatings Technology, 206, 4449-4454. http://dx.doi.org/10.1016/j.surfcoat.2012.04.094

[33] Zhang, J., Wang, L. and Wang, A. (2007) Preparation and Properties of Chitosan-g-Poly(Acrylic Acid)/Montmorillonite Superabsorbent Nanocomposite via in Situ Intercalative Polymerization. Industrial and Engineering Chemistry Research, 46, 2497-2502. http://dx.doi.org/10.1021/ie061385i

[34] Liu, Y., Liu, W., Chen, W., Sun, L. and Zhang, G. (2007) Investigation of Swelling and Controlled-Release Behaviors of Hydrophobically Modified Poly(Methacrylic Acid) Hydrogels. Polymer, 48, 2665-2671. http://dx.doi.org/10.1016/j.polymer.2007.03.010

[35] de Moura, M., Aouada, F. and Mattoso, L. (2008) Preparation of Chitosan Nanoparticles Using Methacrylic Acid. Journal of Colloid and Interface Science, 321, 477-483. http://dx.doi.org/10.1016/j.jcis.2008.02.006

[36] Neto, B., Mata, A., Lopes, M., Rossi-Bergmannd, B. and Ré, M. (2014) Preparation and Evaluation of Chitosan-Hydrophobic Silica Composite Microspheres: Role of Hydrophobic Silica in Modifying Their Properties. Power Technology, 225, 109-126. http://dx.doi.org/10.1016/j.powtec.2013.10.046

[37] Zou, H., Wu, S. and Shen, J. (2008) Polymer/Silica Nanocomposites: Preparation, Characterization, Properties, and Applications. Chemical Reviews, 108, 3893-3957. http://dx.doi.org/10.1021/cr068035q

[38] Treccani, L., Klein, T., Meder, F., Pardun, K. and Rezwan, K. (2013) Functionalized Ceramics for Biomedical, Biotechnological and Environmental Applications. Acta Biomaterialia, 9, 7115-7150. http://dx.doi.org/10.1016/j.actbio.2013.03.036

[39] Copello, G., Mebert, A., Raineri, M., Pesenti, M. and Diaz, L. (2011) Removal of Dyes from Water Using Chitosan Hydrogel/ $\mathrm{SiO}_{2}$ and Chitin Hydrogel/SiO${ }_{2}$ Hybrid Materials Obtained by the Sol-Gel Method. Journal of Hazardous Materials, 186, 932-939. http://dx.doi.org/10.1016/j.jhazmat.2010.11.097

[40] Zou, H., Wu, S. and Shen, J. (2008) Polymer/Silica Nanocomposites: Preparation, Characterization, Properties, and Applications. Chemical Reviews, 108, 3893-3957. 
Scientific Research Publishing (SCIRP) is one of the largest Open Access journal publishers. It is currently publishing more than 200 open access, online, peer-reviewed journals covering a wide range of academic disciplines. SCIRP serves the worldwide academic communities and contributes to the progress and application of science with its publication.

Other selected journals from SCIRP are listed as below. Submit your manuscript to us via either submit@scirp.org or Online Submission Portal.
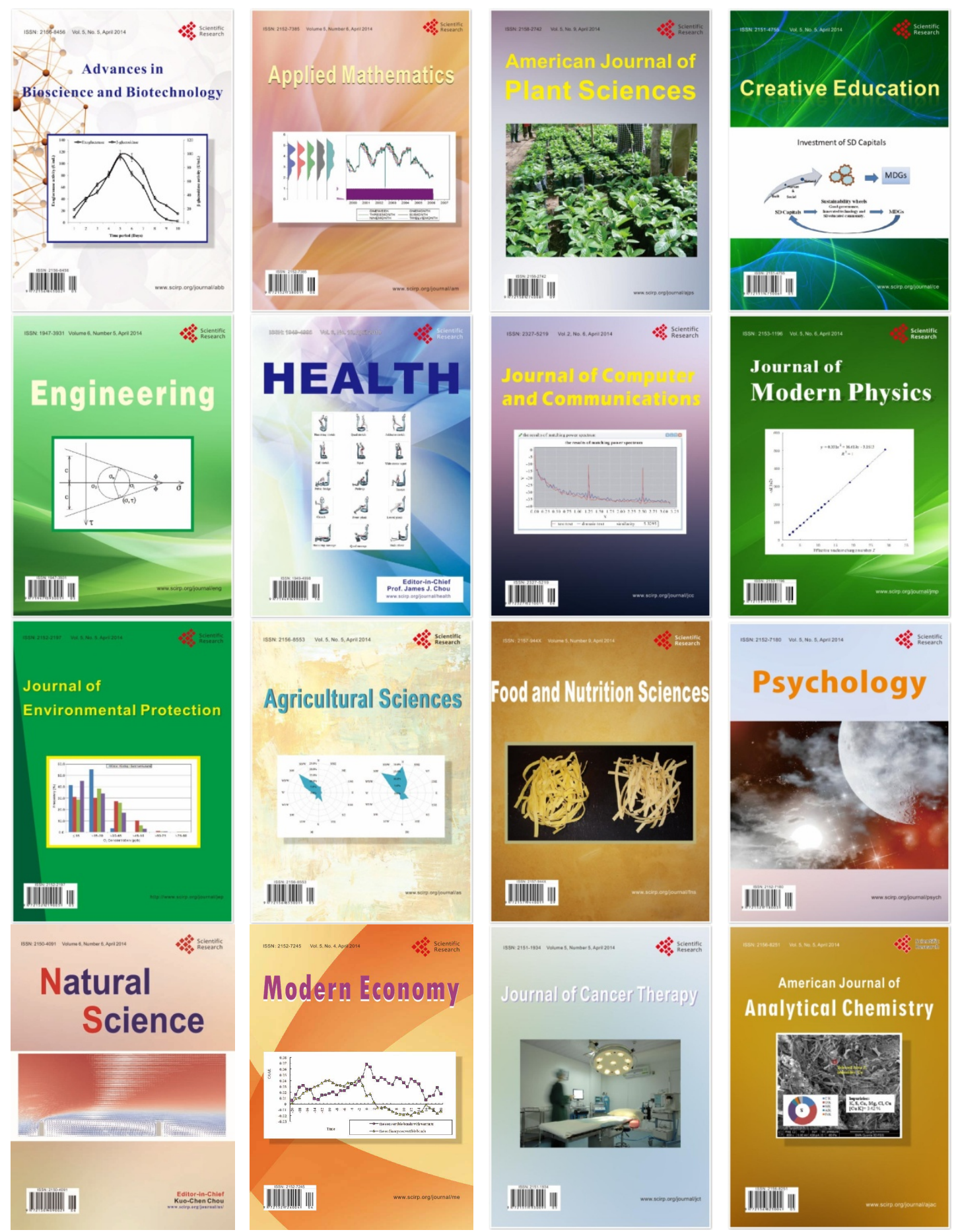